\title{
DESIGN AND EVALUATION OF COVERALL FOR PESTICIDE APPLICATORS USING AN ERGONOMIC FRAMEWORK
}

\author{
Sanjay Guria, and Huiju Park, Cornell University, USA
}

Keywords: coverall, design, evaluation, ergonomics

Introduction: There is a continued need to improve coverall design in compliance with established safety standards (Ashdown \& Watkins, 1992; Huck, Maganga \& Kim, 1997). At the same time, evaluating clothing fit for design development is challenging as it depends on subjective responses of wearer perceptions and preference (Watkins, 1995; Yu, 2004). Gordon, Lastovich, Bye, \& Labat (2014), proposes a data triangulation model integrating technology, user responses and expert evaluation for assessing coverall designs. However, the model fails to synthesize factors such as environment and work condition challenges to user needs. The latter has been studied in a focus group study by Guria \& Park (2017) along with behavioral responses of users of protective coveralls. The aim of this paper is to present the design and evaluation of a new coverall for pesticide applicators using an ergonomic framework (Figure 1) that includes user, task and environmental considerations.

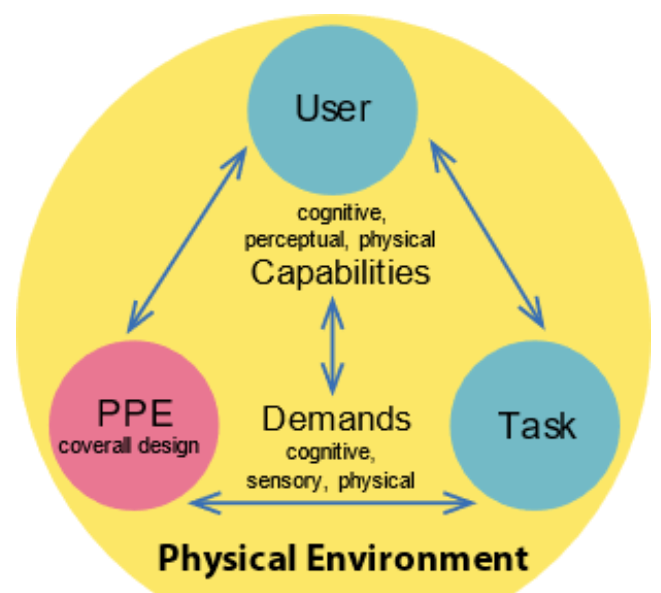

Figure 1: Ergonomic framework adopted for coverall design

Methods: A multi-method approach was adopted for designing and evaluating a new coverall design for pesticide applicators. Five male (height: $177.10 \pm 3.44 \mathrm{cms}$, weight: $80.56 \pm 8.93 \mathrm{kgs}$; BMI: $25.7 \pm 3.3$, white non-Hispanic) pesticide applicators participated in the study. Environmental assessment and anthropometric dimensions of participants were recorded during phase one, which guided the design development of the coverall prototype. Ergonomic evaluation for fit and mobility was performed during phase two. Each participant wore either the

Page 1 of 4

(c) 2019 The author(s). Published under a Creative Commons Attribution License (https://creativecommons.org/licenses/by/4.0/), which permits unrestricted use, distribution, and reproduction in any medium, provided the original work is properly cited.

ITAA Proceedings, \#76 - https: //itaaonline.org 
regular fitting coverall (control) based on American National Standard Institute (ANSI) and International Safety Equipment Association (ISEA) wear test standard (ANSI/ISEA 101, 2014) or the new coverall design (new) in random order along with necessary personal protective equipment (PPE) and performed nine body postures (ISO 16602, 2007). Range of motion (ROM) data collected through photo and video documentation, subjective ratings of fit and mobility (5point Likert scale with mobility rating scale ranging from 1 (very restrictive) to 5(very easy to move) and fit satisfaction rating scale ranging from 1 (very dissatisfied) to 5(very satisfied)) was assessed to compare fit and mobility of both existing and new coverall design.

Results \& Discussions: Environment: Environmental assessment of greenhouses (mean temperature: $18{ }^{\circ} \mathrm{C}$ to $30.8{ }^{\circ} \mathrm{C}$ and relative humidity: $31.6 \%$ to $85.5 \% \mathrm{RH}$ ) revealed material properties (evaporative resistance and thermal insulation values) of the coverall material as important factors to be taken into consideration in design development (Table 1). Ratings by the participants show an enhanced sense of security ascribed to the material of the new coverall design as compared to the existing coverall. They found it more comfortable to wear for longer hours (mean time inside coverall: 1.5 to 2 hours including mixing, loading, spraying and cleaning). A participant responded, "I can be in this suit for hours".

Table 1: Evaporative resistance and thermal insulation values of the two coverall materials

\begin{tabular}{|l|l|l|}
\hline Coverall prototypes tested & $\begin{array}{l}\text { Evaporative Resistance } \\
\left(\mathrm{Pa} .{ }^{\circ} \mathrm{C} / \mathrm{W}\right)\end{array}$ & $\begin{array}{l}\text { Thermal Insulation } \\
\left({ }^{\circ} \mathrm{C} . \mathrm{m}^{2} / \mathrm{W}\right)\end{array}$ \\
\hline Control coverall & 78.57 & 0.32 \\
\hline New coverall & 60.25 & 0.27 \\
\hline
\end{tabular}

Task: Subjective evaluation of the two coverall designs revealed the new coverall design to have a higher rating for fit satisfaction (4-satisfied) as compared to the existing coverall (3-neutral). Further, it offered greater range of mobility (4-easy to move) as compared to existing coverall design (3- neutral). Supplemental comparative study of the nine body posture exercises found that the new coverall design offered greater range of motion for both the upper and lower body. However, the existing coverall performed better in donning (mean time: control: $2 \mathrm{~min}: 26 \mathrm{sec}$, treatment: $2 \mathrm{~min}: 52 \mathrm{sec}$ ) and doffing (mean time: control: $1 \mathrm{~min}: 25 \mathrm{sec}$, treatment: $1 \mathrm{~min}: 33 \mathrm{sec}$ ) timings compared to the new coverall design. But shorter donning and doffing timings are not effective indicators of better coverall design.

User: Based on the user needs (Guria \& Park, 2017), the new design incorporated attached sleeve envelopes and booties. This was appreciated by participants and it made them feel safe as it offered better integration with facemask, gloves and footwear. Inner seams were sealed to offer better protection against chemical splashes. The coverall design was more form fitting to individual body type along with reduction in inseam length for arms and legs. This eliminated the risk of the coverall snagging on the edges of sharp objects thereby reducing the risk of contamination. Also, to mitigate the issue of heat stress, a Powered Air Purifying Respirator

(c) 2019 The author(s). Published under a Creative Commons Attribution License (https://creativecommons.org/licenses/by/4.0/), which permits unrestricted use, distribution, and reproduction in any medium, provided the original work is properly cited.

ITAA Proceedings, \#76 - https: //itaaonline.org 
(PAPR) hood with blower was included in the new design. Participants felt the dual layered PAPR hood protected them better from overhead liquid splashes during foliage pesticide application. An integrated face mask offered very good visibility and gave participants freedom to sport facial and long hair. A rear entry design was proposed to reduce the risk of contamination and enable better protection and fit of the facemask with the hood.

It was observed from the study that incorporating the ergonomic framework of environmental and task assessment to user needs enabled the investigators to offer better and more satisfactory design solutions to coverall design. Some of the limitations of the study was the small sample size, single geographical location and non-inclusion of female participants. To allow freedom to the creative design process the investigators put aside the component of cost, a deciding factor for disposable coverall purchase. To mitigate the issue of heat stress, considering the body map of sweating pattern (Smith \& Havenith, 2011) can be a useful tool for the development of appropriate coverall design.

Future research: Incorporating the fourth dimension of technology (3D motion capture system, computer software for custom pattern development, 3D scanning) can provide a more robust framework to the ergonomic model to provide a comprehensive understanding of coverall design issues and offer better fit satisfaction. Also, this would allow to conform to gender specific requirements better, especially female population. Future studies with a larger sample size will provide a direction to standardization of better coverall design.

\section{References}

American National Standard Institute, (2014). ANSI/ISEA 101-2014: American National Standard for Limited-Use and Disposable Coveralls--Size and Labeling Requirements. International Safety Equipment Association. Arlington, VA.

Ashdown, S.P. \& Watkins, S.M. (1992). Movement analysis as the basis for the development and evaluation of a protective coverall design for asbestos abatement.

Gordon, L., Lastovich, T., Bye, E., \& Labat, K. (2014). A Protocol for the Evaluation of Coverall Fit. International Textile and Apparel Association (ITAA), 1-3.

Guria, S., \& Park, H. (2017). Assessment of greenhouse pesticide applicators' needs for personal protective gear (PPG). International Textile and Apparel Association (ITAA), 1-3.

Huck, J., Maganga, O., and Kim, Y. (1997). Protective overalls: Evaluation of garment design and fit. Int. J. Clothing Sci. Technol., 9(1), 45-61.

In J.P. McBriarty \& N.W. (Eds.), Performance of protective clothing: ASTM STP 1133 (pp660674). Philadelphia, PA: ASTM.

International Organization for Standardization. (2007). Protective clothing for protection against chemicals - Classification, labelling and performance requirements (ISO/DIS Standard No. 16602:2007). Retrieved from https://www.iso.org/standard/45985.html

Page 3 of 4

(c) 2019 The author(s). Published under a Creative Commons Attribution License (https://creativecommons.org/licenses/by/4.0/), which permits unrestricted use, distribution, and reproduction in any medium, provided the original work is properly cited.

ITAA Proceedings, \#76 - https://itaaonline.org 
Smith, C. J., \& Havenith, G. (2011). Body mapping of sweating patterns in male athletes in mild exercise-induced hyperthermia. European Journal of Applied Physiology, 111(7), 1391-1404. https://doi.org/10.1007/s00421-010-1744-8

Yu, W. (2004). Objective evaluation of clothing fit. In J. Fan, W. Yu, \& L. Hunter (Eds.), Clothing Appearance and Fit: Science and Technology (pp. 72-88). Cambridge, England: Woodland Publishing Limited. 